\title{
Metástase múltipla de carcinoma de células escamosas ocular em bovino: dois casos*
}

\section{Multiple metastasis of eye squamous cell carcinoma in cattle: two cases}

\author{
Rogério Elias Rabelo, ${ }^{* *}$ Fabiano José Ferreira de Sant'Ana, ${ }^{* * *}$ Valcinir Aloísio Scalla Vulcani, ${ }^{* * * *}$ Lorena Ferreira Silva, ${ }^{* * * *}$ \\ Andressa Sabine Rabbers, ${ }^{* \star * * *}$ Thaynã Chaves e Santos, ${ }^{* \star * * * *}$ Caroline Rocha de Oliveira Lima, ${ }^{* \star * * * * *}$ \\ Luiz Antônio Franco da Silva*********
}

\begin{abstract}
Resumo
Dentre os diversos tumores que acometem bovinos, o carcinoma de células escamosas ocular é o mais frequente nessa espécie, determinando prejuízos consideráveis nos criatórios. São vários os fatores envolvidos na patogênese, porém a constante exposição à luz ultravioleta e a quantidade reduzida de pigmentação em torno dos olhos estão relacionados com a maior prevalência. A neoplasia ocorre principalmente na pálpebra inferior, membrana nictitante e a junção corneoescleral. São descritos dois casos incomuns de carcinoma de células escamosas oculares que resultaram em metástases múltiplas para linfonodo regional, glândulas salivares e pulmão em vacas criadas do Sudoeste de Goiás. Histopatologia de todos os casos revelou proliferação de blocos hipercelulares de queratinócitos neoplásicos. As células possuíam citoplasma amplo e eosinofílico, núcleo arredondado, central e basofílico, com cromatina frouxa e um a dois nucléolos grandes e proeminentes. Havia anisocariose e anisocitose acentuadas e sete a dez mitoses em dez campos de 400X. Exposição prolongada aos raios solares e despigmentação dos tecidos primários afetados foram considerados fatores predisponentes importantes.
\end{abstract}

Palavras-chave: doenças de bovinos, neoplasia, olho, pulmão.

\begin{abstract}
Among the various tumor affecting cattle, ocular squamous cell carcinoma is the most common in this species, causing considerable losses to farms. Several factors involved in the pathogenesis, but constant exposure to ultraviolet light and the reduced amount of pigmentation around the eyes are related to higher prevalence. The tumor occurs mainly in the lower eyelid, the nictitating membrane and corneoescleral junction. Two unusual cases of ocular squamous cell carcinoma that resulted in multiple metastases to regional lymph node, salivary gland and lung in cows created in southwest Goiás. Histopathology exams of all cases revealed hypercellular proliferation of neoplastic keratinocytes blocks. Cells had broad and eosinophilic cytoplasm, rounded nuclei and central basophilic, with loose chromatin and one to two large and prominent nucleoli. There was marked anisocytosis and anisokaryosis seven to ten mitoses in ten 400X fields. Prolonged exposure to sunlight and depigmentation of the affected primary tissues were considered important predisposing factors.
\end{abstract}

Keywords: cancer, cattle diseases, eye, lung.

\section{Introdução}

Em países de clima tropical como o Brasil, as neoplasias de pele e seus anexos estão sendo cada vez mais diagnosticadas na medicina veterinária em consequência da constante exposição dos animais à radiação ultravioleta. Essas enfermidades ocasionam, portanto, perdas econômicas significativas devido à redução da vida produtiva, gastos com tratamentos e condenação de carcaças em abatedouros (Anderson e Badzioch, 1991; Meuten, 2002; Ramos et al., 2007).

Dentre as diversas neoplasias de ocorrência em bovinos, o carcinoma de células escamosas ocular (CCEO) é o mais frequente nessa espécie (Smith, 2006; Ramos et al., 2007; Radostits et al., 2010). Aponta-se como raças mais afetadas aquelas com áreas oculares despigmentadas, como Hereford, Charolês, Simental e Holandesa. A neoplasia acomete principalmente a pálpebra inferior, membrana nictitante e a junção corneoescleral (Blowey e Weaver, 1991; Meuten, 2002; Ramos et al., 2007; Radostits et al., 2010).

O CCEO apresenta aspecto maligno, no qual as células epidérmicas se diferenciam em queratinócitos, tendo crescimento lento e localmente invasivo, causando destruição, embora com baixo potencial metastático (Yager e Scoot, 1993; Souza, 2005; Scopel et al., 2007; Ramos et al., 2007). Metástases de CCEOs

\footnotetext{
${ }^{*}$ Recebido em 27 de fevereiro de 2014 e aceito em 4 de dezembro de 2014.

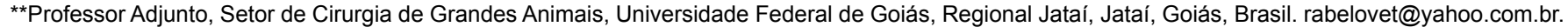
${ }^{* * *}$ Professor Adjunto, Laboratório de Patologia Veterinária, Universidade de Brasília, Brasília, Distrito Federal, Brasil.

****Professor Adjunto, Setor de Anatomia Animal, Universidade Federal de Goiás, Regional Jataí, Jataí, Goiás, Brasil.

*****Aluna do Programa de Residência, Universidade de Brasília, Brasília, Distrito Federal, Brasil.

******Aluna do Programa de Pós-Graduação em Ciência Animal, Mestrado, Universidade Federal de Goiás, Goiânia, Goiás, Brasil.

******Aluna do Programa de Residência, Universidade Federal de Goiás, Regional Jataí, Jataí, Goiás, Brasil.

******* Professora Doutora da Universidade Estadual de Goiás, Campus Jataí, Jataí, Goiás, Brasil.

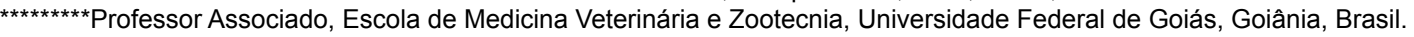


para outros órgãos e tecidos são consideradas raras e, quando ocorrem, podem ser observadas em animais com tumores grandes (Cordy, 1990; Smith, 2006).

São vários os fatores envolvidos na patogênese do CCEO, porém a constante exposição à luz ultravioleta e a quantidade reduzida de pigmentação em torno dos olhos estão relacionados com a maior prevalência (Meuten, 2002; Smith, 2006).

A neoplasia se desenvolve por meio de uma série de estágios pré-malignos que consistem em placas hiperplásicas ou epidérmicas e papilomas, os quais, após meses e anos progredindo in situ, finalmente se transformam em CCEOs não invasivos e, posteriormente, em CCEOs invasivos. Os tumores nictitantes se estendem à base da membrana e cartilagem de forma mais rápida, com disseminação para dento da órbita e tecidos vizinhos, ocorrendo mais precocemente do que os tumores que envolvem o globo ocular (Smith, 2006).

Esse estudo tem como objetivo descrever os aspectos clínicos e patológicos de dois casos de CCEO em bovinos com metástases múltiplas para órgãos adjacentes e distantes do sítio primário.

\section{Relato dos casos}

O caso 1 consistiu de uma vaca Holandesa, com dez anos de idade, que apresentou disfagia e emagrecimento progressivo. A vaca pertencia a um rebanho de aptidão leiteira de criação semi-intensiva no município de Jataí, Goiás. As vacas eram submetidas a duas ordenhas diárias e permaneciam a maior parte do dia expostas ao sol em piquetes de Brachiaria spp. ou Andropogon spp. Ao exame clínico foi verificado escore corporal ruim e uma massa firme na região da mandíbula direita (Figura 1). O exame da cavidade oral não apresentou alterações significativas. Durante a anamnese foi relatado que o animal havia sido submetido a um procedimento cirúrgico, há aproximadamente um ano, para exérese da terceira pálpebra direita devido à presença de neoformação que, após confirmação histopatológica, tratava-se de um CCEO bem diferenciado. Devido ao estado geral debilitante, prognóstico reservado, agravamento do quadro do animal e prévio acordo do proprietário, optou-se pela eutanásia.

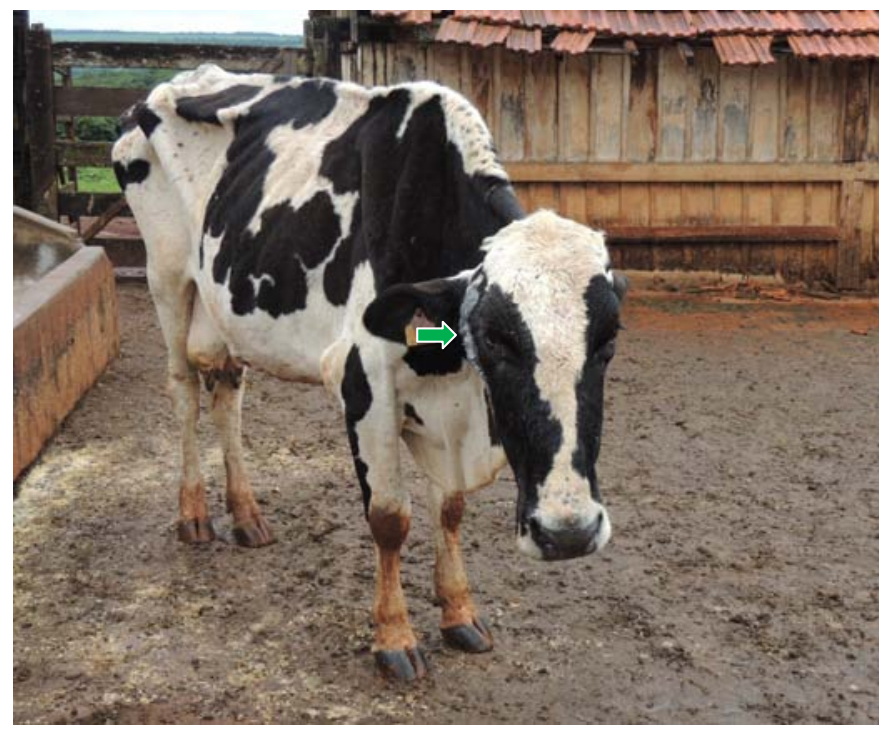

Figura 1: Caso 1: bovino, carcinoma de células escamosas metastático Nota-se animal com estado geral debilitado e nódulo na região mandibular (seta) um ano após exérese de neoplasma na terceira pálpebra.
No caso 2, uma vaca Holandesa 7/8, com doze anos de idade, apresentou emagrecimento progressivo, sialorreia e uma neoformação proliferativa no olho direito com evolução clínica de doze meses. A vaca fazia parte de um rebanho leiteiro de criação semi-intensiva do município de Portelândia, Goiás. Os bovinos eram submetidos a três ordenhas diárias e permaneciam grande parte do dia expostas ao sol em piquetes de Brachiaria brizantha. No exame físico, notou-se que o escore corporal era muito ruim e que havia na região mandibular direita (altura da extremidade dorsal do ramo da mandíbula) um aumento de volume de aproximadamente $15 \mathrm{~cm}$ de diâmetro. Diante do prognóstico bastante desfavorável e ciência do proprietário, foi indicada a eutanásia do bovino.

Nos dois casos, durante a necropsia, foram coletados fragmentos de vários órgãos, incluindo pulmão, linfonodo submandibular e glândula parótida. Os mesmos foram fixados em solução de formol a $10 \%$, sendo posteriormente clivados, processados rotineiramente para histopatologia e corados pela hematoxilina-eosina (HE).

Macroscopicamente, no caso 1 , a massa mandibular correspondia à glândula parótida que media $11,0 \times 8,0 \times 3,5 \mathrm{~cm}$ e era firme, irregular e possuía superfície de corte multilobulada e esbranquiçada com área central enegrecida e numerosos pontos ou áreas lineares amareladas (Figura 2A). Todos os lobos do pulmão apresentavam numerosos nódulos arredondados, variando de 0,5 a $2 \mathrm{~cm}$ de diâmetro, firmes, irregulares, pouco delimitados, que, ao corte, apresentavam superfície amarelada de aspecto granular e delimitada por área esbranquiçada adjacente (Figura 2B). O linfonodo submandibular direito estava moderadamente aumentado de volume. Ao corte, observou-se massa irregular, firme e amarelada, com áreas esbranquiçadas. As alterações macroscópicas detectadas no nódulo mandibular, glândula parótida e pulmão eram muito similares.

Na necropsia do caso 2, evidenciou-se uma massa ocular firme, irregular, esbranquiçada com áreas puntiformes amareladas, medindo 8,0 X 5,5 X 4,5 cm, que afetava a córnea e esclera e causava invasão e atrofia dos tecidos perioculares adjacentes. Todos os lobos pulmonares apresentavam nódulos multifocais a coalescentes, esbranquiçados, firmes, proeminentes e que variavam de 0,4 a $1,0 \mathrm{~cm}$ de diâmetro. Foi observada na glândula salivar parótida uma massa firme, irregular, esbranquiçada, medindo 14,0 X6,5 X3,0 cm. A glândula submandibular possuía uma massa com as mesmas características descritas na glândula parótida, que media $6,0 \times 3,5 \times 1,0 \mathrm{~cm}$. Nesse último órgão, notou-se uma área central de necrose na superfície de corte. O fígado apresentava áreas multifocais enegrecidas, arredondadas e deprimidas, que foram interpretadas como telangiectasia.

Histologicamente, as lesões dos dois casos, em todos os órgãos acometidos, foram extremamente semelhantes e consistiam de massas hipercelularizadas formadas por blocos de células bastante coesas, poligonais a arredondadas, sustentados por estroma fibrovascular abundante. O citoplasma apresentavase amplo a moderado, eosinofílico, homogêneo e indistinto. O núcleo era arredondado, central, basofílico, com cromatina frouxa e um a dois nucléolos grandes e proeminentes. Havia anisocariose e anisocitose acentuadas, com relação núcleo e citoplasma de 6:1, sendo observadas sete a dez mitoses em dez campos de 400X. Foram registradas, ainda, células neoplásicas individualizadas, com núcleo em picnose ou cariorrexia. No 


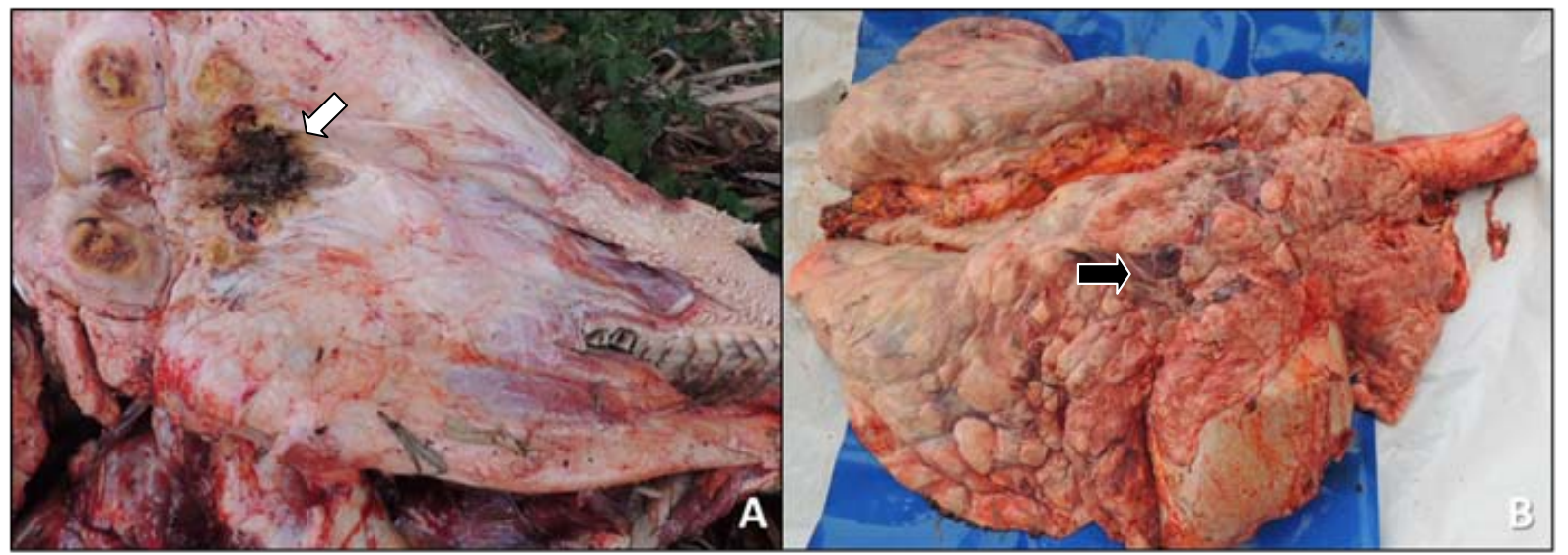

Figura 2: Caso 1: bovino, carcinoma de células escamosas metastático. A. Glândula parótida apresenta nódulo metastático amarelado com área central enegrecida (seta branca). B. Há numerosos nódulos firmes (seta preta) distribuídos por todos os lobos pulmonares.

interior de alguns blocos celulares havia áreas irregulares e extensas de necrose e estruturas arredondadas, compostas por lamelas concêntricas e eosinofílicas de queratina (pérolas córneas) de tamanhos variados. Áreas multifocais de infiltrado composto por linfócitos e neutrófilos foram encontradas em meio às células neoplásicas. No pulmão, a proliferação neoplásica substituía os alvéolos e bronquíolos e ocluía ocasionalmente seus lúmens, exibindo caráter infiltrativo e sem encapsulamento (Figura 3). Nos linfonodos afetados, todas as regiões do órgão estavam infiltradas pelas células neoplásicas. Não foram observadas alterações histológicas significativas em outros órgãos.

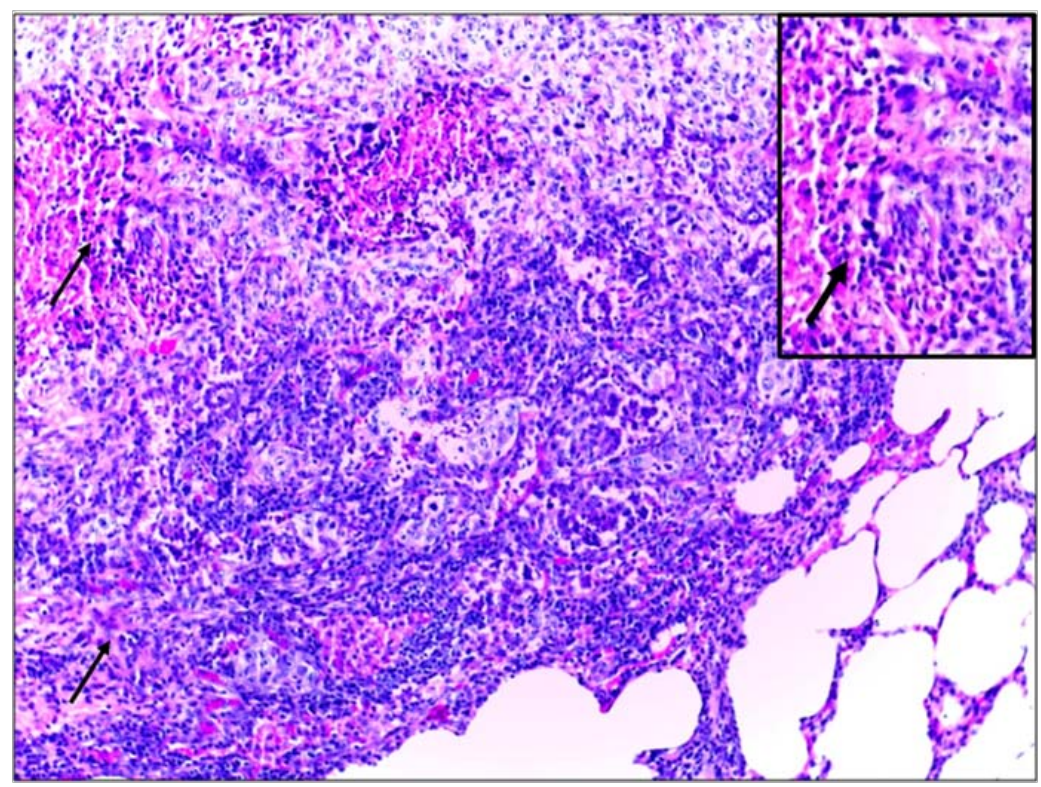

Figura 3: Caso 1: bovino, carcinoma de células escamosas. Pulmão. Há área focalmente extensa que substitui os alvéolos (setas escuras), composta por queratinócitos neoplásicos em meio a áreas irregulares de necrose e infiltrado de linfócitos (seta escura, em destaque na imagem ampliada, canto superior direito). HE, Obj. 10X.

Portanto, o diagnóstico morfológico confirmou a suspeita clínica de carcinoma de células escamosas com metástase para pulmão, linfonodo submandibular e glândula parótida.

\section{Discussão}

Apesar do caráter multifatorial, o sistema semi-intensivo e região tropical, com alta incidência de raios ultravioletas em que o animal era manejado, foram considerados os principais fatores de risco no desencadeamento do CCEO nos casos aqui descritos. Diferentes autores relacionam a exposição solar com o aumento da ocorrência de CCE, principalmente quando esses apresentam áreas da epiderme despigmentadas (Meuten, 2002; Radostits et al., 2010; Souza et al., 2011). A idade, sexo e aptidão do animal também foram considerados fatores de relevância a ocorrência da enfermidade, visto que, por questão de manejo na bovinocultura leiteira, as fêmeas têm sido mais acometidas, principalmente quando apresentam idade mais avançada (Spadbrow e Hoffmen, 1980; Meuten, 2002; Barros et al, 2006). Com relação à raça, devido às características fenotípicas do Holandês, contendo muitas áreas despigmentadas, constitui outro importante fator de risco para desenvolvimento do CCEO (Meuten, 2002; Ramos et al., 2007; Keller et al., 2008).

O quadro clínico progressivo de disfagia e emagrecimento apresentado pelo bovino provavelmente estão relacionados com a disseminação do neoplasma pelo organismo, bem como pela dor e incômodo que as metástases determinam nos hospedeiros (Meuten, 2002). É possível que a sialorreia notada no segundo caso esteja relacionada com o comprometimento das glândulas salivares submandibular e parótida acometidas e com a dificuldade de escoamento de saliva pela deglutição.

O CCEO do primeiro caso teve sua origem na terceira pálpebra, enquanto que no caso 2 a córnea foi o provável sítio primário de crescimento neoplásico. A disseminação do neoplasma ocorreu provavelmente por via hematógena e ou linfática para linfonodo regional, glândulas salivares e pulmão. A possibilidade de invasão local dos neoplasmas oculares para as glândulas parótidas não foi considerada, pois não havia comunicação anatômica entre esses tecidos no caso 2 e, porque no caso 1 , no momento da exérese não foi observado comprometimento 
de tecidos adjacentes ao olho. Embora o CCE seja localmente invasivo e recidivante, as metástases desse neoplasma são raramente observadas (Summers, 1979; Keller et al., 2008). Outro fator discrepante com a literatura é quanto ao tamanho do tumor. Geralmente, observam-se metástases em animais com tumores grandes (Cordy, 1990), porém o caso 1 desse estudo apresentava, inicialmente, um tumor de terceira pálpebra de dimensões pequenas. Há uma descrição de CCEO em bovino com invasão para o encéfalo através dos nervos cranianos (Barros et al., 2006). Nos dois casos aqui relatados, não se notou invasão ou metástase para o encéfalo.

A caracterização microscópica dos fragmentos de biópsia e de necropsia dos presentes casos, arranjados em forma de cordões

\section{Referências}

ANDERSON, D. E.; BADZIOCH, M. Association between solar radiation and ocular squamous cell carcinoma in cattle. American Journal of Veterinary Research, v. 52, p. 784-788, 1991.

BARROS, R. R.; RECH, R. R.; VIOTT, A. M. Carcinoma de células escamosas no olho de bovinos com invasão cerebral através dos nervos cranianos. Ciência Rural, Santa Maria, v. 36, n. 5, p. 1651-1654, 2006.

CORDY, D.R. Tumors of nervous system and eye. In: MOULTON D. J. Tumors of domestic animais. 3. ed. Berkeley: University of California, p. 640-665, 1990.

FERNANDES, C. G. Neoplasias em ruminantes e eqüinos. In: RIET-CORREA, F.; SHILD, A. L.; LEMOS R. A. A.; BORGES, J. R. J. Doenças de ruminantes e eqüídeos. 3. ed. Santa Maria: Editora Pallotti, p. 650-656, 2007.

JONES, T. C.; HUNT, R. D; KING, N. M. Patologia veterinária. 6. ed. Barueri: Manole, 2000. p. 831-886.

KELLER, D.; RÖNNAU, M.; GUSMÃO, M. A.; TORRES, M. B. A. M. Casuística de carcinoma epidermóide cutâneo em bovinos do Campus Palotina da UFPR. Acta Scientiae Veterinariae, Porto Alegre, v. 36, p. 155-159, 2008.

MEUTEN, D. J. Tumors in domestic animals. 4. ed., Ames: lowa State Press, 2002, 788 p.

RADOSTITS, O. M.; GAY, C. C.; BLOOD, D. C.; HINCHCLIFF, $\mathrm{K}, \mathrm{W}$. Clínica veterinária: um tratado de doenças dos bovinos, ovinos, suínos, caprinos e equinos. 9. ed. Rio de Janeiro: Guanabara Koogan, 2010. p. 535. de células epidérmicas queratinizados, em forma de pérolas lamelares, proliferadas ou não, estendidas através da derme, corrobora com outras descrições encontradas na literatura (Barros et al., 2006; Fernandes, 2007; Ramos et al., 2007).

\section{Conclusão}

Com base nos achados epidemiológicos, clínicos, macroscópicos e, principalmente, histopatológicos, firmou-se o diagnóstico de carcinoma de células escamosas primário da terceira pálpebra (caso 1) e da córnea (caso 2) com metástases múltiplas para órgãos como pulmão, linfonodo submandibular e glândulas parótida e submandibular.

RAMOS, A. T.; NORTE, D. M.; ELIAS, F.; FERNANDES, C. G. Carcinoma de células escamosas em bovinos, ovinos e equinos: estudo de 50 casos no sul do Rio Grande do Sul. Brazilian Journal of Veterinary Research and Animal Science, São Paulo, v. 44, p. 5-13, 2007.

SCOPEL, D.; SPADER M. B.; GUIM, T. N.; DANIELI, V. M.; FERNANDES, C. G. Estudo retrospectivo da casuística de carcinoma de células escamosas em felinos, bovinos, caninos, equinos e ovinos entre os anos de 2002 e 2006 no Lrd/Ufpel. In: CONGRESSO DE INICIAÇÃO CIENTÍFICA DE PESQUISA E RESPONSABILIDADE AMBIENTAL, 16., 2007, Pelotas. Anais... Pelotas: UFPEL, 2007.

SMITH, B. P. Tratado de medicina interna de grandes animais. 3. ed. São Paulo: Manole, 2006. 1784 p.

SOUZA, T. M. Estudo retrospectivo de 761 tumores cutâneos em cães. 2005. 296 f. Dissertação (Mestrado em Patologia Veterinária) - Universidade Federal de Santa Maria, Santa Maria, 2005.

SOUZA, I. K. F.; MOREIRA, T. R.; SILVA, S. P.; SOUZA, S. N. G.; SOUZA, R. S.; TORMES, M. B.; NEVES, K. A. L. Carcinoma de células escamosas periocular em bovinos criados no Pará, Brasil. Revista de Ciências Agrárias, v. 54, n. 2, p. 113-116, 2011.

SPADBROW, P. B.; HOFFMANN, D. Bovine ocular squamous cell carcinoma. Veterinary Bulletin, v. 50, p. 449-459, 1980.

SUMMERS, B. A. Squamous cell carcinoma metastatic to the brain in a cow. Veterinary Pathology, v. 16, p. 132-133, 1979.

YAGER, J. A.; SCOOT, D.W. The skin and appendges. In: JUBB, K. V. F.; KENNEDY, P. C.; PALMER N. Pathology of domestic animals. 4. ed. San Diego: Academic Press, p. 531-738. 1993. 